\title{
Continuation of Indoor Prescribed Antibiotics in the Outpatient Treatment of Neonatal Sepsis
}

\author{
Islam SMR ${ }^{1}$, Talukder $\mathrm{K}^{1}$, Akter $\mathrm{M}^{2}$, Khatoon $\mathrm{S}^{1}$ \\ ${ }^{1}$ Department of Paediatrics, Centre for Woman and Child Health, Dhaka, Bangladesh \\ ${ }^{2}$ Research Department, Centre for Woman and Child Health, Dhaka, Bangladesh \\ e-mail: rafiqped@yahoo.com
}

\begin{abstract}
Neonatal sepsis is a common problem whose antibiotic treatment is usually recommended whilst admitted in hospital for at least 10-14 days. Families in Bangladesh however are reluctant to stay in hospital to complete the treatment for such a long time due to reasons such as financial difficulties and either or both are working parents. This leads to incomplete treatment of neonatal sepsis. We hypothesised that after initial improvement in neonatal sepsis with injectable antibiotics whilst admitted, the same treatment could be safely continued in the outpatient setting to complete the full course. This intervention study was carried out in 66 newborns (0-28 days) recruited at the time of admission with suspected sepsis in the Department of Paediatrics, Centre for Woman and Child Health (CWCH), Dhaka. After investigations, treatment was initiated with injectable antibiotics according to clinical diagnosis and severity. Families who agreed to stay and complete the treatment as inpatient were given the complete course of antibiotics in hospital as IPD group and those who wanted to shorten their stay in hospital, were discharged with injectable antibiotics and follow-up in the outpatient department as OPD group. Data were analysed on 59 neonates, 37 in the OPD and 22 in the IPD group, admitted to hospital between April 2014 and December 2015. There were no readmissions or complications in either group, but one newborn died in the IPD group. Cure rate was 100\% in both OPD and IPD groups. Average duration of hospital stay was $3.95 \pm 1.76$ days and $6.14 \pm 2.99$ days in the OPD and IPD groups respectively. Treatment cost per patient was 5,823 $\pm 3,752$ Bangladesh Taka (BDT) and $7,082 \pm 6,520$ BDT in the OPD and IPD groups respectively. Findings of this study suggest that early discharge with injectable antibiotics as an outpatient is a safe and cost effective option for neonatal sepsis.
\end{abstract}

Key words: Antibiotic, Hospital stay, Neonatal sepsis, Treatment cost

\section{Introduction}

Neonatal sepsis is a major cause of morbidity and mortality in developing countries like Bangladesh. It is reported that sepsis and pneumonia were the causes of death in $27 \%$ of newborns. ${ }^{1}$ The early and efficient diagnosis of neonatal sepsis remains a difficult task due to delayed development of signs and symptoms. Early diagnosis and treatment with suitable antibiotics are usually started in hospital. Although ideally antibiotic regimens should be selected on the basis of local organism isolation and antibiotic sensitivity, in reality antibiotics are chosen on the basis of broad epidemiological information about organisms in developing countries. In neonatal sepsis, treatment with combined antibiotics is given for at least 7 days, for which families have to stay in hospital for a long time with increased treatment cost. This length of stay is one of the major barriers to completing the full treatment course in neonatal sepsis in developing countries, especially for working parents to overcome this problem single 
dose antibiotic (ceftriaxone) once daily can be given in outpatient department. ${ }^{2-5}$

Thus, there is a need to provide treatment with injectable antibiotics in the outpatient department (OPD) after initial treatment and improvement in the inpatient setting. It is expected that this will reduce the duration and hence the cost of hospital stay. Furthermore, families will feel more comfortable completing the full course of treatment at home. The aim of this study was to assess whether discharging newborns with sepsis to continue treatment as an outpatient with a single antibiotic (ceftriaxone) or a combination regimen that was prescribed during admission, was safe and cost effectiveness.

\section{Materials and Methods}

This intervention study was carried out between April 2014 and December 2015 at the Centre for Woman and Child Health $(\mathrm{CWCH})$ in Ashulia- a peri-urban area to the northwest of Dhaka Metropolitan area in Bangladesh. Any newborn baby (0-28 days) admitted to $\mathrm{CWCH}$ who had a provisional diagnosis of neonatal sepsis was included in this study. Neonates with hypoxic ischaemic encephalopathy (HIE), congenital heart disease, very low birth weight $(<1,500 \mathrm{~g})$, meconium aspiration syndrome, major congenital anomaly or birth injury (cephalhaematoma, intracranial haemorrhage) were excluded from the study. Among the 66 neonates who fulfilled the inclusion criteria, a total of 37 did not want to complete the total duration of treatment in hospital and were categorised for early discharge (OPD group).Twenty-two neonates were treated according to our hospital protocol in the IPD. We took verbal consent from recruited parents after discussion in detail about the purpose of the study, risks, benefits and possible outcomes. All selected families participated voluntarily and confidentiality of all information was strictly maintained. Ethical clearance was taken from the Ethical Review Committee of the CWCH.

After admission, the neonates were assessed for features of sepsis such as convulsions, respiratory rate $\geq 60$ breaths/min, severe chest indrawing, grunting, bulging fontanelle, pus draining from the ear, redness around the umbilicus, core (rectal) temperature $\geq 37.7^{\circ} \mathrm{C}$ or $<35.5^{\circ} \mathrm{C}$, lethargy or coma, reduced movements, inability to feed, cyanosis, digital capillary refill time $>2$ seconds and oxygen saturation $<92 \%$. To support the clinical suspicion of sepsis the following investigations were occasionally done - CRP (abnormal $\geq 6 \mathrm{mg} / \mathrm{L}$ ), WBC count (abnormal $<5 \times 10^{3} / \mu \mathrm{L}$ or $>15 \times 10^{3} / \mu \mathrm{L}$ ), total neutrophil ratio (IT ratio) (abnormal $>0.2$ ), blood $\mathrm{CS}$, urine RE and C/S, CSF study and chest Xray - and treatment started. Antibiotics were given according to standard doses used for neonatal sepsis such as Ampicillin (100 $\mathrm{mg} / \mathrm{kg} / \mathrm{d}), \quad$ Gentamicin $\quad(7.5 \mathrm{mg} / \mathrm{kg} / \mathrm{dose})$, Cefotaxime $(50 \mathrm{mg} / \mathrm{kg} / \mathrm{dose})$, Ceftriaxone (75$100 \mathrm{mg} / \mathrm{kg} / \mathrm{dose}$ ), Meropenem (40 mg/kg/dose) or Vancomycin $(10 \mathrm{mg} / \mathrm{kg} / \mathrm{dose})$ in single or in combination regimens. After 3-4 days of initial treatment, babies' condition usually improved with good feeding or suckling and stable vital signs. They were divided into two groups - those who agreed to continue full course of treatment staying in hospital as IPD group, and those who did not agree to stay in hospital and were discharged with injectable antibiotics and followed up as OPD group.

The process of discharge with injectable antibiotic and OPD follow- up had the following features: ${ }^{6}$

a. After initial improvement (good feeding/suckling, vital signs stable) babies from the OPD group were discharged early;

b. The baby was discharged with IV cannula in situ with a plan to continue antibiotics that had already been given in the IPD;

c. A register was maintained for those who came for daily injectable antibiotics;

d. A medical officer (MO) examined the baby to identify any problems when they came for their injections;

e. Families brought their newborns for a final follow-up seven days after completion of the antibiotic course and the final assessment was done by a paediatrician in the outpatient department;

f. Parents were advised to come back to hospital immediately if they saw any deterioration in their baby;

g. Communication was maintained with parents by mobile phone; and

h. Parents were counselled on how to take care of the IV cannula at home. 
Data were collected in a prescribed form by an indoor physician about the following: baby's sex, mode of delivery, place of delivery, admission age (hours), admission weight (g), clinical features, specific diagnosis, duration of hospital stay, duration of OPD antibiotic course, outcome after seven days of OPD treatment and follow up procedure. Admission cost data were collected from computerised hospital financial records.

Data was entered using Epi-info 7 and analysed using SPSS version 16.

After data entry and cleaning, the proportion of babies with successful outcome with outpatient treatment was estimated and compared with the proportion of babies with successful outcome with inpatient treatment.

\section{Results}

A total of 66 neonates were recruited for the study. Among them, 39 were in the OPD group and 27 in the IPD group. A total of seven patients were excluded (OPD 2 and IPD 5) due to reasons such as lost to follow-up (4), left against medical advice (LAMA) (1), death (1) and referred to a higher centre (1). Finally, data were analysed for 59 neonates (OPD 37 and IPD 22) (figure 1).

Figure 1: Procedures for patient selection, management, and outcome

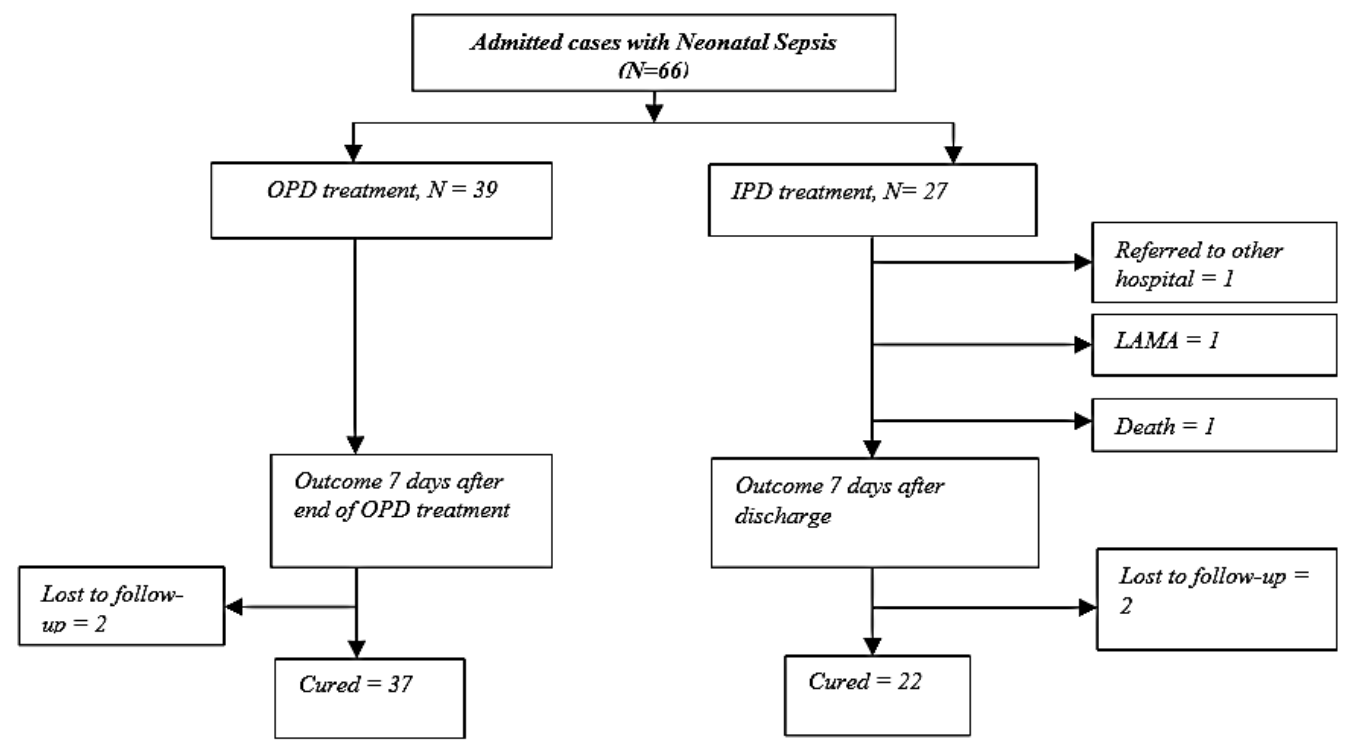

There were no statistically significant differences in either socio-demographic (table I) or common clinical features (table II) at admission between these two groups. Both OPD and IPD groups cure rates were $100 \%$ and there were no readmissions or complications in either group. The average hospital stay in the OPD group was $3.95 \pm 1.76$ days and in the IPD group was $6.14 \pm 2.99$ days.

Average (SD) hospital cost in the OPD group was Bangladesh Taka (BDT) 5,823 $\pm 3,752$ and in the IPD group BDT 7,082 $\pm 6,520$ (table III). There were no statistically significant differences between the two groups in the types of regimens used (table IV).

Table I: Comparison of socio-demographic characteristics between neonates treated in OPD and IPD

\begin{tabular}{|c|c|c|c|}
\hline & $\begin{array}{c}\text { OPD } \\
\mathbf{N}=37(\%)\end{array}$ & $\begin{array}{c}\text { IPD } \\
\mathbf{N}=22(\%)\end{array}$ & $p$ value \\
\hline \multicolumn{4}{|c|}{ Household head's occupation } \\
\hline Office worker & $20(54)$ & $11(52.4)$ & 0.44 \\
\hline Others & $11(29.7)$ & $8(38.1)$ & \\
\hline Businessman & $6(16.2)$ & $1(4.8)$ & \\
\hline Unemployed & $0(0)$ & $1(4.8)$ & \\
\hline Male Neonate & $24(64.9)$ & $12(54.5)$ & 0.58 \\
\hline \multicolumn{4}{|l|}{ Mode of delivery } \\
\hline Normal & $21(56.8)$ & $13(59.1)$ & 1.00 \\
\hline Caesarean & $16(43.2)$ & $9(40.9)$ & \\
\hline \multicolumn{4}{|l|}{ Place of delivery } \\
\hline $\mathrm{CWCH}$ & $13(35.1)$ & $5(23.8)$ & 0.41 \\
\hline Home & $14(37.8)$ & $9(42.9)$ & \\
\hline Other facilities & $10(27)$ & $7(33.3)$ & \\
\hline
\end{tabular}


Table II: Comparison of clinical features between neonates treated in the OPD with those treated in the IPD

\begin{tabular}{|c|c|c|c|}
\hline & $\begin{array}{c}\text { OPD } \\
\mathrm{N}=37 \\
(\%)\end{array}$ & $\begin{array}{l}\text { IPD } \\
\mathrm{N}=22 \\
(\%)\end{array}$ & $\begin{array}{c}p \\
\text { value }\end{array}$ \\
\hline \multicolumn{4}{|l|}{ Admission weight } \\
\hline$<2500 \mathrm{~g}$ & $15(40.5)$ & $\begin{array}{l}15 \\
(68.2)\end{array}$ & 0.06 \\
\hline$\geq 2500 \mathrm{~g}$ & $22(59.5)$ & $7(31.8)$ & \\
\hline \multicolumn{4}{|l|}{ Onset of sepsis } \\
\hline Early sepsis (within 72h) & $23(62.2)$ & $\begin{array}{l}13 \\
(59.1)\end{array}$ & 1.00 \\
\hline $\begin{array}{l}\text { Late Sepsis (more than } \\
72 \mathrm{~h})\end{array}$ & $14(37.8)$ & $9(40.9)$ & \\
\hline Not able to feed & $17(45.9)$ & $\begin{array}{l}14 \\
(63.6)\end{array}$ & 0.28 \\
\hline Oxygen saturation $(\leq 95 \%)$ & $16(43.2)$ & $\begin{array}{l}10 \\
(45.5)\end{array}$ & 1.00 \\
\hline Convulsion & $5(13.5)$ & $0(0)$ & 0.15 \\
\hline $\begin{array}{l}\text { Breathing difficulties } \\
\text { (Respiratory rate } \geq 60 \\
\text { breaths/min) }\end{array}$ & $8(21.6)$ & $8(36.4)$ & 0.24 \\
\hline Severe chest indrawing & $4(10.8)$ & $7(31.8)$ & 0.08 \\
\hline Nasal flaring & $2(5.4)$ & $7(31.8)$ & 0.01 \\
\hline Reduced movement & $11(19.7)$ & $\begin{array}{l}11 \\
(50.0)\end{array}$ & 0.17 \\
\hline Grunting & $4(10.8)$ & $4(18.2)$ & 0.46 \\
\hline \multicolumn{4}{|l|}{ Core Temperature } \\
\hline$\geq 37.7^{\circ} \mathrm{C}$ (fever) & $5(13.5)$ & $6(27.3)$ & 0.21 \\
\hline$<35.5^{\circ} \mathrm{C}$ (hypothermia) & $2(5.4)$ & $1(4.5)$ & \\
\hline Normal & $30(81.1)$ & $\begin{array}{l}15 \\
(68.2)\end{array}$ & \\
\hline Lethargic or unconscious & $7(18.9)$ & $4(18.2)$ & 1.00 \\
\hline No suckling at all & $3(8.1)$ & $1(4.5)$ & 1.00 \\
\hline Chest crepitations & $2(5.4)$ & $5(22.7)$ & 0.09 \\
\hline Cyanosis & $1(2.7)$ & $4(18.2)$ & 0.06 \\
\hline $\begin{array}{l}\text { Digital capillary refill time } \\
>3 \mathrm{~s}\end{array}$ & $0(0)$ & $2(9.1)$ & 0.14 \\
\hline
\end{tabular}

Table III: Average hospital stay duration and cost

\begin{tabular}{lrlll}
\hline & & $\begin{array}{l}\text { OPD, N=37 } \\
\text { Mean } \pm \text { SD }\end{array}$ & $\begin{array}{l}\text { IPD, N=22 } \\
\text { Mean } \pm \text { SD }\end{array}$ & $\begin{array}{l}\text { P } \\
\text { value }\end{array}$ \\
\hline $\begin{array}{l}\text { Average } \\
\text { hospital } \\
\text { (days) }\end{array}$ & stay & $3.95 \pm 1.76$ & $6.14 \pm 2.99$ & 0.001 \\
$\begin{array}{l}\text { Average } \\
\text { antibiotic (days) }\end{array}$ & $3.49 \pm 1.19$ & - & \\
$\begin{array}{l}\text { Average } \\
\text { (BDT) cost }\end{array}$ & $5823 \pm 3752$ & $7082 \pm 6520$ & 0.35 \\
hospital & & & \\
admission & & & \\
\hline
\end{tabular}

Table IV: Patterns of antibiotic use for OPD and IPD groups

\begin{tabular}{|c|c|c|c|c|c|}
\hline \multirow[t]{2}{*}{ Antibiotic } & & \multirow{2}{*}{$\begin{array}{c}\text { Starting } \\
\text { OPD } \\
\mathbf{N}=\mathbf{3 7} \\
(\%)\end{array}$} & \multicolumn{3}{|c|}{ Final } \\
\hline & & & $\begin{array}{c}\text { IPD } \\
\mathbf{N}=22 \\
(\%)\end{array}$ & $\begin{array}{c}\text { OPD, } \\
\mathbf{N}=\mathbf{3 7} \\
(\%)\end{array}$ & $\begin{array}{c}\text { IPD } \\
\mathbf{N}=22 \\
(\%)\end{array}$ \\
\hline $\begin{array}{l}\text { Ampicillin } \\
\text { Gentamicin }\end{array}$ & + & $5(13.5)$ & $4(18.2)$ & $3(8.1)$ & $1(4.5)$ \\
\hline $\begin{array}{l}\text { Cefotaxime } \\
\text { Gentamicin }\end{array}$ & + & $9(24.3)$ & $6(27.3)$ & $6(16.2)$ & $4(18.2)$ \\
\hline $\begin{array}{l}\text { Ceftriaxone } \\
\text { Gentamicin }\end{array}$ & + & $0(0)$ & $1(4.5)$ & $0(0)$ & $1(4.5)$ \\
\hline Cefotaxime & & $5(13.5)$ & $2(9.1)$ & $5(13.5)$ & $2(9.1)$ \\
\hline Ceftriaxone & & $\begin{array}{l}12 \\
(32.4)\end{array}$ & $6(27.3)$ & $\begin{array}{l}18 \\
(48.6)\end{array}$ & $9(40.9)$ \\
\hline Meropenem & & $1(2.7)$ & $0(0)$ & $0(0)$ & $2(9.1)$ \\
\hline $\begin{array}{l}\text { Cefotaxime } \\
\text { Amikacin }\end{array}$ & + & $1(2.7)$ & $0(0)$ & $2(5.4)$ & $0(0)$ \\
\hline $\begin{array}{l}\text { Ampicillin } \\
\text { Flucloxacilin }\end{array}$ & + & $1(2.7)$ & $0(0)$ & $1(2.7)$ & $0(0)$ \\
\hline $\begin{array}{l}\text { Ceftriaxone } \\
\text { Flucloxacilin }\end{array}$ & + & $2(5.4)$ & $2(9.1)$ & $1(2.7)$ & $2(9.1)$ \\
\hline $\begin{array}{l}\text { Cefotaxime } \\
\text { Flucloxacilin }\end{array}$ & + & $0(0)$ & $1(4.5)$ & - & - \\
\hline Ampicillin & & $1(2.7)$ & $0(0)$ & - & - \\
\hline $\begin{array}{l}\text { Meropenem } \\
\text { Vancomycin }\end{array}$ & + & - & - & $1(2.7)$ & $0(0)$ \\
\hline Ciprofloxacin & & - & - & $0(0)$ & $1(4.5)$ \\
\hline
\end{tabular}

In both OPD and IPD patients the most commonly used antibiotic regimen was Ceftriaxone alone followed by combined Cefotaxime with Gentamicin.

No significant differences were found between the OPD and IPD groups with regard to the limited number of investigations done (table $\mathrm{V}$ ).

Table V: Investigation results

\begin{tabular}{|c|c|c|c|}
\hline $\begin{array}{l}\text { Investigation } \\
\text { (numbers } \\
\text { investigated) }\end{array}$ & $\begin{array}{l}\text { OPD }^{*} \\
\text { n }(\%)\end{array}$ & $\begin{array}{l}\text { IPD }^{*} \\
\text { n }(\%)\end{array}$ & $P$ value \\
\hline CRP & & & \\
\hline $\begin{array}{l}\text { On } \quad \text { admission } \\
(\mathrm{OPD}=30, \mathrm{IPD}=18)\end{array}$ & $14(46.7)$ & $8(44.4)$ & 1.00 \\
\hline $\begin{array}{l}\mathrm{WBC} \quad(\mathrm{OPD}=31, \\
\mathrm{IPD}=17)\end{array}$ & $6(80.6)$ & $15(68.2)$ & 0.69 \\
\hline $\begin{array}{l}\text { IT ratio }(\mathrm{OPD}=13 \text {, } \\
\mathrm{IPD}=4)\end{array}$ & $3(23.1)$ & $0(0)$ & 0.54 \\
\hline $\begin{array}{l}\text { Blood C/S }(\mathrm{OPD}=9, \\
\mathrm{IPD}=5)\end{array}$ & $4(44.4)$ & $3(60.0)$ & 1.00 \\
\hline $\begin{array}{l}\text { CSF study }(\mathrm{OPD}=1 \text {, } \\
\mathrm{IPD}=2)\end{array}$ & $0(0)$ & $1(50.0)$ & 1.00 \\
\hline $\begin{array}{l}X \text {-ray chest }(\mathrm{OPD}=3 \text {, } \\
\mathrm{IPD}=7)\end{array}$ & $2(66.7)$ & $4(57.1)$ & 1.00 \\
\hline
\end{tabular}




\section{Discussion}

According to current guidelines for treatment of neonatal sepsis, Ampicillin and Gentamicin are used as $1^{\text {stline }}$ drugs. ${ }^{7,8}$ Ceftriaxone or Cefotaxime can be used for serious bacterial infections in the neonatal period. ${ }^{2,8,9}$ Once daily dose and its pharmacokinetics favour Ceftriaxone for use in the first three months of life. ${ }^{10}$ One major concern with the use of Ceftriaxone in neonates is its increased risk of hyperbilirubinaemia especially in preterm babies. In this study, preterm babies were excluded, and used Ceftriaxone in term mature babies without jaundice.

In this study, it was found that there were no differences regarding cure rate, readmission or any complication between the OPD and IPD groups. A study from a developed country showed that in early discharge with home injectable antibiotic therapy there were no serious complications or treatment failure; in addition, costs were lower compared with continued inpatient treatment. ${ }^{6}$

The main limitation of this study was that a diagnosis of neonatal sepsis was made mainly on the basis of clinical signs and symptoms because of inadequate microbiological facilities in our hospital. A further limitation was that all patients allocated to OPD treatment did not attend our hospital for follow-up treatment. Instead, they completed the rest of their course of antibiotics in other health facilities. In these cases, outcome information was obtained over mobile phone.

\section{Conclusion}

Despite these limitations we conclude that early discharge with injectable antibiotic therapy as OPD treatment of neonatal sepsis is safe and cost effective in a resource limited setting.

Acknowledgments: The authors acknowledge the support of all physicians and nurses of the Department of Paediatrics of the CWCH. They are also grateful to the families of all newborns who participated in the study.

Conflicts of interest: All the authors declare that they have no conflicts of interest.

\section{Reference}

1. Chowdhuri HR, Thompson S, Ali M, Alam N, Yunus M, Streatfield PK. Causes of neonatal deaths in a rural subdistrict of Bangladesh: implications for intervention. J Health PopulNutr. 2010; 28(4):37582.

2. Darmstadt GL, Batra M, Zaidi AK. Parenteral antibiotics for the treatment of serious neonatal bacterial infections in developing country settings. Pediatr Infect Dis J. 2009; 28(1 Suppl):S37-42.

3. Saez-Llorens X, McCracken GH Jr. Clinical phamacology of antimicrobial agents. In: Remington JS, Klein JO, editors. Infectious Diseases of the Fetus and Newborn Infant. 5th ed. Philadelphia, PA: WB Saunders; 2001.

4. Wiese G. Treatment of neonatal sepsis with ceftriaxone/gentamicin and with azlocillin/gentamicin: a clinical comparison of efficacy and tolerability. Chemotherapy. 1988; 34:158-163.

5. James J, Mulhall A, de Louvois J. Ceftriaxone clinical experience in the treatment of neonates. $\mathrm{J}$ Infect. 1985; 11:25-33.

6. Wagner CL, Wagstaff P, Cox TH, Annibale DJ. Early discharge with home antibiotic therapy in the treatment of neonatal infection. J Perinatol. 2000; 20 (6):346-50

7. Obiero CW, Seale AC, Berkley JA. Empiric treatment of neonatal sepsis in developing countries. Pediatr Infect Dis J. 2015 Jun; 34(6):659-61.

8. Medscape, Neonatal sepsis medication, Access on 9 April, 2017. Available from http://emedicine.medscape.com/article/978352medication\#2.

9. World Health Organization. Pocket book of hospital care for children: guidelines for the management of common childhood illnesses. 2nd ed. Geneva, Switzerland; 2013. p. 56.

10. Rondanelli R, Ragazzi MB, Stronati M, Calvi M, Lombardi G, Rondini G. Pharmacokinetics of Ceftriaxone in the first three months of life. Pediatr Med Chir. 1992; 14(1):55-9. 